\title{
O PERIGO POPULISTA NA HIPÓTESE DE TRANSIÇÃO DA DEMOCRACIA DELEGATIVA PARA A DE TIPO CONTÍNUA NO BRASIL
}

José Ribas Vieira ${ }^{1}$

Gabriel Lima Marques ${ }^{2}$

\section{Resumo}

Desde 2013 o mundo assiste o Brasil se transformar em um grande palco de reclamações. Descontentamentos dos mais variados, reivindicações das mais plurais, ideologias das mais diversas, parecem cada qual querer pôr luz sobre algum aspecto defeituoso da vida política nacional. Subjacente a essa realidade, porém, o presente artigo parte do pressuposto de que ainda que haja divergências de leitura e de respostas, o que o mesmo assume estar em jogo no centro desses movimentos é o modelo de Democracia que se quer transmitir para as próximas gerações. Afinal, por ser a democracia um processo de constante mutação e aperfeiçoamento, a emergência no cenário político de cidadãos desconfiados das instâncias investidas de poder, se a princípio, porque favorece o accountability, pode ter o ponto positivo de encaminhar o Brasil para a saída de uma experiência delegativa e rumar para uma de tipo contínua. Por outro lado, é possível também que a desconfiança geral manipulada pelo populismo, o que nesse contexto pode surgir, possa terminar favorecendo o continuísmo.

Palavras-chave: Democracia; Desconfiança; Rendição de Contas; Populismo.

\footnotetext{
${ }^{1}$ Pós-doutorado em Direito na Université Montpellier I - CERTE, com bolsa CAPES (1985-86). Professor Visitante na Univesity of Illinois at Urbana-Champaign (1989). Professor Visitante na University of Florida e Professor Titular aposentado de Direito Constitucional. Atualmente é Professor Associado da Pontifícia Universidade Católica do Rio de Janeiro. Professor Titular da Universidade Federal do Rio de Janeiro. Consultor ad hoc da Fundação de Amparo à Pesquisa do Estado de São Paulo. Pesquisador-coordenador do Grupo de Pesquisa CNPq Observatório da Justiça Brasileira - OJB-UFRJ. E-mail: jribas@puc-rio.br ${ }^{2}$ Doutorando em Direito Público na Universidade do Estado do Rio de Janeiro - UERJ. Professor (40 horas - DE) de Direito Constitucional da Universidade Federal do Amapá - UNIFAP.E-mail: gabriel-marques@hotmail.com
} 


\section{INTRODUÇÃO}

Para compreender o Brasil de hoje é preciso situar o país em um processo de crítica a performance da democracia que se inicia em junho de 2013 (AVRITZER, 2016, p. 08). Não é que tal como alude Marcos Nobre (2013, p. 57), este movimento tenha sido “[...] raio em céu azul [...]”. Na verdade, estudiosos e alguns segmentos sociais já há algum tempo se ocupavam do trabalho denunciante. Ocorre, porém, e isso é uma marca indelével que torna aquela presença nas ruas especial, que as jornadas de 2013 assumiram a finalidade de manifestar a existência de um descontentamento generalizado da sociedade para com as deficiências da maquinaria política posta. Assim, vendo-se pouco aptos em obrigar os governantes a realizar ações ou tomar certas medidas que estivessem de acordo com suas aspirações (responsiveness), os cidadãos perceberam-se diante de uma falta de alternativas senão a de intensificar a presença no espaço público, multiplicando o monitoramento e consequentemente as exigências de justificação (accountability) direcionadas ao poder institucionalizado (ROSANVALLON, 2015, p. $31)^{3}$

Tendência global (BURKE, 2014, p. 28), ${ }^{4}$ tal giro de postura se constitui no resgate de uma figura que historicamente sempre existiu, mas que até recentemente esteve relegada ao segundo plano: aquela do povo ao mesmo tempo, vigilante, veto e juiz. Quer dizer, ainda que seja um dado indiscutível mundo afora o de que a confiança na capacidade das instituições político-representativas de oferecerem respostas adequadas aos sentimentos sociais tenha declinado consideravelmente nas últimas décadas (MOISÉS, 2010, p. 60), justo porque os cidadãos não se veem, não se ouvem e nem muito menos se reconhecem mais nas ações de seus representantes (ROUSSEAU, 2015, p. 28). Como um contraponto simultâneo, o que vem ocorrendo a título de resposta não é o pleito pela destruição da representação, mas o crescimento da convicção de que o repertório da expressão cívica para persuadir a condução da res publica, vai além do voto (ROSANVALLON, 2015, p. 31). ${ }^{5}$

O resultado disso, o que se quer indicar aqui neste trabalho, pode ser o começo no caso brasileiro da superação de uma experiência delegativa da representação ${ }^{6}$ e a inauguração de um tipo de democracia

\footnotetext{
${ }^{3}$ Sobre tais atitudes, a que Pierre Rosanvallon chama de sanções de poder, o autor (ROSANVALLON, 2015, p. 31) explica que as mesmas teriam por objeto colocar a reputação do poder à prova. E neste sentido, considerando que a democracia eleitoral é sempre situada. Como as sanções de poder, por outro lado, tanto apresentam um caráter permanente quanto podem ser realizadas por qualquer indivíduo, é certo, em última análise, que terminam por ampliar e facilitar a intervenção da sociedade nos rumos tomados pelo poder político.

${ }^{4}$ Indo além, Sara Burke (2014, p. 31) chama a atenção para o fato de que os povos do mundo estão cada vez mais "[...] perturbados por necessidades econômicas que não são atendidas, porque são cada vez mais excluídos dos processos políticos em que são tomadas decisões neste campo [...]".

${ }^{5}$ Ambiguidade que Colin Crouch (2004, p. 40) chamou a atenção para um contexto dito pós-democrático.

${ }^{6} \mathrm{O}$ que caracteriza uma democracia de tipo delegativa é que aqueles que são eleitos tornam-se fiadores do interesse nacional, e por isso mesmo são autorizados a atuar da forma como lhes parece ser a mais conveniente, relegando-se aos delegantes a condição de meros espectadores passivos (O’DONNELL, 1991, pp. 30-31).
} 
denominada pela ciência política de contínua, onde tal como o deus Janus da mitologia romana, os cidadãos se assumem em uma simbiose permanente entre a face "corpo político" e a face "homem de rua" (ROUSSEAU, 2015, pp. 82-83). ${ }^{7}$ Contudo, se a partir daí, é fato que as eleições persistem enquanto instrumentos necessários para a instituição tanto de governos quanto para a composição de parlamentos. Como as contestações de toda sorte para com os legitimados pelas urnas passam a ser uma constante, não apenas pela via institucional, mas agora também por poderes intermitentes, fragmentários e informais. Em tal âmbito, apesar de a princípio a percepção do ato de votar como uma ferramenta de cessão completa e ilimitada da soberania se tornar cada vez mais superada, tal peculiaridade não exclui o risco dessa lógica ser revertida pelo crescimento do populismo (CHERESKY, 2015, pp. 115-119).

Assim disposto, vale registrar que para desenvolver esse argumento, o presente paper encontra-se divido em três partes. Na primeira delas a intenção é apresentar a formação do que se nomeia enquanto democracia contínua, deixando consignado em tal oportunidade o papel estruturante da desconfiança como uma contrapartida a debilitação da representação. Em seguida, a proposta direciona-se no sentido de situar as jornadas de junho de 2013 como o possível start brasileiro na direção desta nova realidade, apontando também aí como os efeitos que desde então vêm se prolongando podem corroborar tal leitura. E por último, o que se busca demonstrar é que se a manifestação da delegação na experiência democrática brasileira é de fato um problema histórico que pode ser superado pelo desenvolvimento de um accountability social, ${ }^{8}$ por outro, a depender do contexto, quando do manejo dessa ferramenta, a mesma pode abrir campo ao populismo e favorecer a reanimação daquela lógica perversa.

\section{A DEMOCRACÍA CONTÍNUA EM CENA: REPRESENTAÇÃO, CRISE E METAMORFOSE}

Se é certo, tal como frequentemente apontado em diversos trabalho, que quanto mais reduzida é uma comunidade, maior acaba por ser a participação de cada um de seus membros na formação da vontade comum (ZIPPELIUS, 1985, p. 198). Também o é, em igual quadra, o fato de que o exercício do poder soberano

\footnotetext{
${ }^{7}$ Dominique Rousseau (2015, p. 85), explica que “[...] a democracia contínua não se reduz a uma forma de governo, já que é uma forma de sociedade. Não é atribuída a um determinado lugar, nem a um espaço, nem a uma geografia, ela é o transbordamento do lugar onde o sistema representativo se realiza e se espalha, isto é, toda a sociedade. A democracia contínua, portanto, distinguisse radicalmente do sistema representativo clássico, que é realizado em um lugar único, a esfera estatal, aquela onde se expressa o 'povocorpo-político' $[. .].]^{\prime}$.

${ }^{8}$ Em sentido semelhante, mas em outros termos, registra Enrique Peruzzotti (2014, p. 275) que "[...] a força, constância e habilidade política destes atores que impulsionam um accountability governamental, colocam em movimento um círculo virtuoso de estimulação e indução entre mecanismos de controle sociais e horizontais que eventualmente são capazes de romper com as dinâmicas perversas que ajudaram a reproduzir a democracia delegativa [...]”.
} 
diretamente pelo povo, pressupõe uma estrutura territorial e social, hoje praticamente inexistente (CANOTILHO, 2003, p. 294). ${ }^{9}$ Neste sentido, dada, portanto, a impossibilidade prática de utilização dos processos da democracia direta, algo que pressupõe a instalação de uma assembleia de cidadãos deliberantes e sem intermediários, chamados estes a tomarem parte em um plebiscito diuturno, o recurso a democracia que se instrumentaliza por intermédio do sistema representativo acaba por ser inevitável (DALLARI, 2003, p. 155). ${ }^{10}$

Essa, aliás, não é uma conclusão diferente daquela a que igualmente se chega desde o tempo das revoluções liberais. Montesquieu (1996, p. 170) mesmo, já afirmava que a liberdade pressupunha que o povo em conjunto se ocupasse diretamente do poder, só que dando um passo atrás, reconhecia na mesma oportunidade ser tal fato impossível no complexo contexto do Estado moderno. O que somado a uma vigorosa suspeita que tinham os teóricos do iluminismo para com as massas, fez da defesa da representação não apenas um meio para solucionar um problema de extensão geográfica e tópica da pólis, mas ainda, uma resposta as dificuldades provocadas pelas paixões e interesses facciosos, inerentes, como se acreditava e se defendia à época, quando os homens governam imediatamente a si mesmos. Desta forma, seria muito mais provável "[...] que a vontade pública, expressa pelos representantes do povo, estivesse em harmonia com o interesse público do que no caso de ser ela expressa pelo próprio povo, reunido para esse fim [...]" (HAMILTON, MADISON \& JAY, 2003, p. 64). ${ }^{11}$

E de modo a que assim fosse, na controvérsia sobre o mandato independente (PITKIN, 1967, p. 145) ${ }^{12}$ venceu, portanto, e como era de se esperar, a tese segundo a qual os representantes seriam pessoas ornadas de duas características a saber, a irresponsabilidade perante os seus eleitores, sendo o mandato destes então irrevogável, bem como a liberdade de atuação política, já que ao serem sufragados para tutelar os interesses de toda a sociedade, não poderiam eles se acharem vinculados a proteger os interesses particulares deste ou daquele grupo específico (AZAMBUJA, 2008, pp. 280-281). Ocorre que daí em diante, se a representação sem vínculos teve por mérito eliminar o particularismo dos corpos intermediários, algo característico do ancien régime, a mesma, porém, em nome de um pretenso interesse geral, terminou na verdade por favorecer, segundo a

\footnotetext{
9 Outra, aliás, não é a conclusão a que chega Norberto Bobbio (2004, p. 65) segundo o qual “[...] a assembleia dos cidadãos - a democracia que Rousseau tinha em mente - é um instituto, como de resto Rousseau sabia muito bem, que pode ter vida apenas numa pequena comunidade, como era a do modelo clássico por excelência, a Atenas do V e do IV séculos, quando os cidadãos não passavam de poucos milhares e a sua assembleia, considerando-se os ausentes por motivo de força maior ou por livre e espontânea vontade, reunia-se com todos juntos no lugar estabelecido [...]".

${ }^{10}$ Por sistema representativo aqui, entende-se tal como aponta Roberto Gargarella (1995) "[...] um ordenamento político destinado a substituir o sistema da democracia direta e mediante o qual um grupo de pessoas leva adiante a tarefa cotidiana de organizar a vida em sociedade, em nome e representação da cidadania [...]"

${ }^{11}$ Clássica, inclusive, é a afirmação do abade Emmanuel Sieyès (2001, p. 72) para quem "[...] o direito de fazer-se representar só pertence aos cidadãos por causa das qualidades que lhes são comuns e não devido aquelas que os diferenciam [...]".

${ }^{12}$ Expressa bem o que foi essa disputa a colocação feita por John Stuart Mill (1878, p. 345), para quem essa lide se centrava em saber se "[...] o membro de uma legislatura deve ser limitado por instruções dos representados. Se deve ele deve ser o órgão dos sentimentos deles ou dos seus próprios $\mathrm{E}$ ainda se deve ser o embaixador deles em um congresso ou seus agentes profissionais, empossados não somente para agir para eles, mas ainda para julgar por eles o que deve ser feito [...]”.
} 
interpretação dada pela esquerda revolucionária que então emergia, a representação apenas da classe que substituíra com seu próprio poder o poder do monarca, qual seja, a burguesia (BOBBIO, 2000, pp. 467-468).

Como resposta a esse processo de elitização, uniu-se para tanto o operariado do século XIX, e em parte o do século XX, em torno de duas frentes de disputas: o alargamento do direito de voto culminando no sufrágio universal, e o desenvolvimento do associacionismo político até a formação dos partidos de massa e o reconhecimento de sua função pública (BOBBIO, 2003, p. 153). ${ }^{13}$ Pensava-se com isso, que abertos os portões da cena política à pluralidade de interesses, aos partidos caberia a função de centros de agregação destes, mediando, portanto, um contato entre heterogeneidade coletiva, neles unificada de um lado, e o parlamento e os membros que o compunham de outro (VERGOTTINI, 2004, p. 220). ${ }^{14}$ Erigido, contudo, o "Estado de partidos", e absorvido inteiramente por eles o canal institucional da representação política, o que se viu pouco a pouco, e de modo diverso, foi uma mudança de rumo que ato contínuo thes foi corroendo o sustento social (CHERESKY, 2006, p. 13). ${ }^{15}$

Assim, às voltas cada vez mais com disputas de poder do que com problemas da vida cotidiana (MANIN, 1997, pp. 253-254), acabaram os partidos no desenrolar dos anos se corrompendo em suas identidades e afastando-se progressivamente de suas bases (QUIROGA, 1996, p. 156), que frustradas, mas conscientes que começavam a estar de suas potencialidades, passaram a lhes relegar progressivamente um segundo plano na tarefa da intermediação política (ROSANVALLON, 2007, pp. 26-27). Com este novel direcionamento, mais perceptível na última década, o espaço da representação foi a partir daí se modificando, e a animação da agenda pública, que antes tinham como únicos ou ao menos principais protagonistas apenas os partidos e seus asseclas, foram em boa medida se alterando, se transferindo e se alargando no vácuo por eles mesmos provocado, a uma gama espontânea, multiforme e marginalizada de atores informais (CHERESKY, 2006, p. 14). O que, embora, tenha de se reconhecer, para alguns autores trata-se do caso de um desvio viciado da democracia representativa rumo a sua derrocada (MANIN, 2013, p. 125). Para outros estudiosos do mesmo assunto, porém, trata-se de uma transformação que longe de substituir as instituições representativas legadas do passado, na verdade contribui para lhes reinventar sob novas bases (KLINGEMAN \& FUCHS, 1998, p. 437;

\footnotetext{
${ }^{13}$ Da mesma forma é o que entende Paulo Bonavides (2000, p. 466) para quem é através do sufrágio universal e da consequente criação de partidos de massas que daí se seguiu, que passa a haver "[...] intervenção política de consideráveis parcelas do povo, dantes excluída de qualquer ingerência na vida pública [...]”.

${ }^{14}$ Tal estratégia, segue Giuseppe de Vergottini (2004, p. 253) pensava-se ser capaz de “[...] harmonizar progressivamente o princípio representativo com o democrático, de modo a assegurar uma correspondência tendencialmente efetiva entre a orientação dos governados, corpo eleitoral, e dos governantes, assembleia e governo, superando a presunção de correspondência ínsita ao princípio representativo [...]".

15 Themístocles Cavalcanti (1969, p. 117) já apontava essa alteração ao afirmar que "[...] uma das consequências da participação das massas na organização do poder e da perplexidade de uma grande parte do eleitorado diante dos problemas que o seu voto terá
} 
NORRIS, 2002, pp. 222-223). ${ }^{16}$

E sob essa incidência, o que se atribui o título de democracia contínua (CHERESKY, 2011, p. 25) ${ }^{17}$, como a confiança, concebida como um instituto que envolve ao mesmo tempo uma dimensão moral de integridade, e outra substancial de perseguição do bem comum, ao contrário da legitimidade, um atributo de viés jurídico e procedimental (DELLA PORTA, 2012, p. 35), torna-se a marca da relação entre governantes e governados. ${ }^{18}$ Ainda que os cidadãos continuem a desempenhar o papel político de eleitor, porque os indivíduos de hoje possuem muito menos expectativas para com a representação formada através dos meios institucionais, do que possuíam em relação a elas seus antepassados. Os mesmos terminam por escolher uma qualquer, dentre as várias opções de candidatos que a eles se apresentam no catálogo eleitoral, mas nem muito bem terminado o pleito, e uma vez que o ato de votar perde o caráter identitário que possuía no passado, já se colocam todos em um estado permanente de supervisão dos atos praticados por aqueles que foram por eles escolhidos (CHERESKY, 2011,pp. 23, 29).

É o que se vê com a formação de inúmeros advocacy groups, que cobrindo um espectro ideológico amplo, ao invés de tencionarem estabilidade, a formação de lideranças ou mesmo o gerenciamento de grandes estruturas burocráticas, assumem cada um no âmbito de sua atuação temática, o firme propósito de arregimentar adeptos efêmeros em torno de bandeiras pontuais (ROSANVALLON, 2015, p. 78) ${ }^{19}$ e de fazer uso, quando necessário for, da ação negativa para defende-las..$^{20}$ Algo que apesar de por longo tempo ter permanecido diminuído fática e normativamente pois associado ao jacobinismo e ao período do terror, agora é recuperado pela cidadania justo com a intenção de induzir ou demover os representantes eleitos na direção do querer social

de resolver, foi de decadência dos partidos, ou melhor, o seu desprestígio, produzindo naquele fenômeno que os franceses chamaram de despolitização, dando maior relevo ao candidato, ou a grupos representativos de interesses [...]".

${ }^{16}$ Segundo Hugo Quiroga (2013, p. 34) não há dúvidas de que a representação estabelecida por sufrágio eleitoral é aquela que institucionalizada, gera obediência, legitima a democracia, e outorga visibilidade a sociedade. Não obstante, tal conceito hoje se expandiu, projetando-se em outras formas de expressão cidadã, que também exercem função de representação. São "formas informais", como associações cívicas diversas, movimentos sociais e outros, que dão mostra de sua distância das representações instituídas, como partidos e sindicatos.

${ }^{17}$ Em tal sentido pontua Isidoro Cheresky (2011, p. 22) que ao mesmo tempo que a evolução contemporânea põe em evidência que o sistema institucional e normativo se encontra em revisão permanente. No mesmo sentido, deve a democracia ser concebida como um sistema não estável. Entretanto, convém destacar, não para afirmar a sua debilidade, mas sim o seu movimento.

${ }^{18}$ Importa aqui a manifestação de Isidoro Cheresky (2008, p. 186), para quem "[...] nas sociedades contemporâneas se expande a desconfiança porque os representantes legais são considerados por seu turno como membros de uma classe que possui interesses próprios. Frente a ela, o cidadão comum, quando não se encontra vencido pela decepção ou pelo ceticismo, exerce uma vigilância constante, e a exerce ainda mais, em uma época de identificações coletivas declinantes [...]".

${ }^{19}$ Aqui, corroborando com tal afirmação, Isidoro Cheresky (2015, pp. 32-33) pontua que "[...] desde as últimas décadas do século XX, se tem registrado na vida cívica uma mudança consistente na direção de uma acentuada desinstitucionalização e na de um enfraquecimento das identificações públicas sobre as quais os cidadãos se sentiam representados. Os indivíduos não se reconhecem predominantemente, como outrora, em identidades imutáveis nem em organizações que os enquadrem, e as numerosas instâncias coletivas que surgem estão marcadas por vínculos distintos, efêmeros e distantes da pertença tradicional [...]". ${ }^{20}$ Expressão sinônima do que Rosanvallon $(2015$, p. 31) chamou de sanções de poder. Ver nota de rodapé no 02. 
(ROSANVALLON, 2015, p. 179). ${ }^{21}$

Acontecimento que, aliás, se acredita precisamente estar ocorrendo também no Brasil contemporâneo, sobretudo, como já mencionado acima, a partir das saídas em massa do povo às ruas no ano de 2013. Na ocasião, o que será visto de forma mais detida no item a seguir, caracterizada por um ambiente de contestação do establishment político, o que parece à primeira vista ter se colocado no espaço de tempo de lá para cá foi o deslocamento de vários personagens sociais de um estado histórico de letargia para outro de presença atual, central e oxigenante do espaço público, favorável ao fortalecimento do accountability (SADER, 2001, pp. 198199). ${ }^{22}$

\section{AS MANIFESTAÇÕES DE 2013: CAUSA, EPISÓDIO E EFEITOS}

O rompimento das manifestações populares de 2013, colocou em evidência uma crise que desde há muito assombra o Brasil (BONAVIDES, 2003, p. 431). ${ }^{23}$ Por conta de um aumento nas tarifas de ônibus, os cidadãos se sentiram à vontade para se fazerem presentes nas ruas e colocar às claras para a classe política, sua insatisfação traduzida nos mais variados matizes quanto ao desencontro existente entre suas pautas, e àquelas levadas adiante pelos representantes formais..$^{24}$

Em reação a este acontecimento, cuidou-se logo de se retirar novamente das mangas o velho chavão da reforma política, e the atribuir o mérito de ser a ressonância mais fidedigna do que estava a sociedade a desejar. Não fosse pelo fato das discussões no parlamento ficarem resumidas quase que exclusivamente em patologias eleitorais, esta seria realmente uma verdade. ${ }^{25}$ Todavia, dado assim não o ser, fica a percepção de uma incapacidade dos detentores de mandato eletivo de enxergar que a crítica do que "aí está", perpetrada pelas praças

\footnotetext{
${ }^{21}$ Para Perry Anderson (2012, p. 217), inclusive, essa é a narrativa mais surpreendente da história política recente.

${ }^{22}$ Henrique Soares Carneiro (2012, p. 13) nesse particular, irá somar coro a tal colocação, afirmando que "[...] a consciência política rebelde, órfã dos aparatos e desconfiada da política institucional, emerge atualmente em manifestações de rebelião, muitas vezes espontâneas, em que até torcidas organizadas, como no Egito, cumprem um papel de vanguarda revolucionária [...]”.

${ }^{23}$ Aprofunda Bonavides (2003, p. 431), “[...] os fracassos da quarta república provocaram em todo o país uma considerável descrença da sociedade no aparelho representativo tradicional. $\mathrm{O}$ emprego deste por mais de um século, não eliminou as oligarquias, não transferiu ao povo o comando e a direção dos negócios públicos, não fortaleceu nem legitimou nem tampouco fez genuína a presença dos partidos no exercício do poder. Ao contrário, tornou mais ásperas e agudas as contradições partidárias em matéria de participação governativa eficaz. Do mesmo passo fez, também, do poder pessoal, da hegemonia executiva e da rede de interesses poderosos e privilegiados, a essência de toda uma política guiada no interesse próprio de minorias refratárias à prevalência da vontade social e sem respaldo de opinião junto das camadas majoritárias da sociedade [...]”.

${ }^{24}$ Roberto Gargarella (2005, p. 60), inclusive, irá afirmar que em uma democracia representativa clássica, a única alternativa com que contam os cidadãos para alterar o rumo das coisas, é a de apresentar queixas por meio de protestos às autoridades.

${ }^{25}$ Basta ver que os temas mais candentes passam pelo debate sobre financiamento público, privado e misto das campanhas. Sistema proporcional, majoritário, distrital, ou distrital misto. Manutenção ou não do instituto da fidelidade partidária. Cláusula de Barreiras. Manutenção ou não da reeleição. E por aí vai. Para mais informações, basta acessar o trabalho elaborado pelo Núcleo de Estudos e
} 
e vias públicas, era assim uma desaprovação a própria representação como institucionalmente posta (LIMONGI, 2013). Isso porque, ao se valer de faixas e gritos com a expressão "sem partidos", ${ }^{26}$ como muito se pôde ver nos movimentos de multidões à época, o que queria a sociedade deixar oportunamente explícito, era que segundo a sua concepção o problema da arena pública passa pela construção e reprodução destes aparelhos, que tendem antes de tudo a reproduzirem a si mesmos, silenciando, ou quando não, excluindo os interesses sociais dos fóruns oficiais de debate (COCCO, 2013).

Prova maior disso, é que a principal diferença nas aglomerações de pessoas de então, foi o fato de que até aquele específico momento, todos os movimentos contestatórios do poder no Brasil, quando mobilizados, estiveram sempre reunidos sob a coordenação de algum grupo político institucionalizado. Assim foi com as agremiações partidárias, sindicais e/ou estudantis no caso das Diretas Já, nos idos de 80, e também com o impeachment do ex-presidente Fernando Collor de Melo no início dos anos 90 (PUJOL, ROCHA \& SAMPAIO, 2014, p. 04).

Já em 2013, houve uma diferenciação na estética. É bem verdade que as mobilizações foram desencadeadas na cidade de São Paulo por grupos apartidários, com o predomínio do Movimento Passe Livre MPL. Porém, o que se viu após uma forte onda de repressão policial nos primeiros dias de protestos, tudo transmitido ao vivo em vários canais de televisão, foi a apreensão do movimento como sendo seu, pelos mais díspares segmentos da sociedade, que com cartazes artesanais e sem nem mesmo carro de som, se fizeram presentes maciçamente nos dias seguintes (GOHN, 2014, pp. 431-433). Ocorrência, aliás, tão surpreendente, que o sociólogo Manuel Castells (2013, pp. 144-145) conseguiu resumir bem, ao pontuar que de forma confusa, raivosa e otimista, foi surgindo uma consciência compartilhada por milhares de pessoas sobre como a dignidade de cada um, o que se verifica na qualidade da saúde, da educação, da segurança e de tantos outros direitos, estava sendo cotidianamente vilipendiada - e as moças e rapazes que apanharam logo no início das manifestações eram a expressão clara de tal indignação - em razão do simples fato dos cidadãos terem se afastado da política.

A partir disso, o que consequentemente se deu nos últimos anos, foi a proliferação de um sem número de círculos de ação cidadã com foco na supervisão dos corpos representativos, e em especial com o uso da internet (MALINI \& ANTOUN, 2013, p. 16). Meio descentralizado, horizontal e rápido, de acesso de conteúdos e de contato entre as pessoas, que tomado como repertório de trabalho para fins de facilitação tanto da articulação de demandas quanto para o de construção de mobilizações, tem a cada dia funcionado mais e mais como um

Pesquisas da Consultoria Legislativa do Senado Federal, intitulado "Resgate da reforma política. Diversidade e pluralismo no legislativo". Disponível em: > http://www2.senadoleg.br/bdsf/item/id/508215<. Acesso em: 13/01/2017.

${ }^{26}$ Algo, aliás, que não é uma expressão unicamente manifesta no Brasil. Basta relembrar frases recentemente utilizadas por levantes populares em outros países, mas que possuíam em si a mesmo a conotação, caso do "Que se vayan todos" na Argentina em 2001, e o "No nos representan" na Espanha em 2011. 
elemento central para a emancipação cidadã (CASTELLS, 2013, pp. 129-130). ${ }^{27}$

Não à toa que a principal estratégia utilizada por seja qual for o coletivo ou movimento, produto cada um em seu nascimento da chamada guarda-chuva do "\#VemPraRua" de junho de 2013, independentemente da bandeira que ostente - se progressista ou reacionária - e do nível de organização a que se submeta, baseia-se justo na técnica do compartilhamento circunvizinho. Isto é, na sucessiva divulgação e replicação de informações entre amigos e conhecidos através das redes sociais, cujo resultado almejado é universalizar uma determinada causa. E assim, como que em um reload permanente do percurso, contagiar e atrair aqueles que estão sentados confortavelmente no sofá de suas casas a se fazerem ora presentes nas vias, praças ou prédios públicos, para constrangerem os atores políticos na base do barulho a se encaminharem em sentido favorável ao que a eles se pleiteia. E ora ainda, para atuarem virtualmente com o mesmo propósito, assinando petições e votando em consultas públicas online, lotando a caixa de e-mail de parlamentares, realizando "vomitaços" em páginas oficiais, vazando dados pessoais, como endereço e o número do telefone celular de membros do governo, e tantos outros modos (MALINI et al.2014, pp. 04-05). ${ }^{28}$

Tais intervenções, na medida em que submetem os detentores do poder à permanente prova, carregam consigo o ponto positivo de favorecer o desenvolvimento de uma verdadeira cultura de accountability (SAGNIÈRE, 2012, p. 147). E neste âmbito, como se trata de um grande equívoco achar que ao lado da dimensão horizontal do conceito de rendição de contas, a qual diz respeito à capacidade de órgãos estatais controlarem as ações desempenhadas pelos agentes públicos. Só existe a dimensão vertical e isolada de cunho eleitoral. Visão restritiva que nada mais faz, do que ignorar o benefício proporcionado pela elevação ao centro da vida pública dessas múltiplas ações realizadas por grupos de cidadãos fora das instituições. ${ }^{29}$ É por isso, que se utilizando de uma concepção mais atual, na qual tão importante mudança seja valorizada, é possível afirmar que o desenvolvimento da mesma pode sim ser um contributo para a substituição da democracia delegativa pela democracia contínua no Brasil (O’DONNELL, 2003; PERUZZOTTI \& SMULOVITZ, 2006, p. 10).

Afinal, uma vez que o que confere a menção a uma democracia como sendo do tipo delegativa, nada mais é do que a existência de instituições representativas, bem como do sistema formal de checks and balances,

\footnotetext{
${ }^{27}$ Complementando, Manuel Castells (2013, p. 134-135) afirma que "[...] em nossa sociedade, a forma fundamental de comunicação horizontal em grande escala baseia-se na internet e nas redes sem fio. Além disso, é por meio dessas redes de comunicação digital que os movimentos vivem e atuam, certamente interagindo com a comunicação face a face e com a ocupação do espaço urbano. Mas as redes de comunicação digital são um componente indispensável na prática e na organização desses movimentos tal como existe [...]".

${ }^{28}$ Em tal sentido, e os próprios exemplos por si só já são a prova cabal, afirma Pierre Rosanvallon que "[...] enquanto a economia institucional das democracias representativas não experimentou nenhuma revolução maior em dois séculos, \{ em matéria de concepção da representação, de exercício da responsabilidade, do papel atribuído as eleições \}, esses poderes de controle se virão consideravelmente enriquecidos e diversificados [...]".
} 
limitado, porém, em seu alcance, por um Executivo que se percebe como a encarnação de toda a nação e que por isso mesmo acusa qualquer atividade de accountability horizontal como sendo um obstáculo às suas ações (O’DONNEL, 1991, pp. 30-31). Logo, na medida em que as sanções sociais ao poder $^{30}$ têm o efeito de potencialmente trazer maior humildade a representação (KEANE, 2009, p. 27), inclusive ao próprio presidente já que restringem a discricionariedade do uso da coisa pública pela elevação do custo político "reputação" (PERUZZOTTI \& SMULOVITZ, 2006, p. 11). O que daí ocorre, é um estímulo para que as agências oficiais desenvolvam sem inibição o seu papel de controle (PERUZZOTTI, 2014, p. 274). ${ }^{31}$

No entanto, como nem tudo é tão simples quanto parece, o que se materializa no fato da linha de fronteira que separa a contrapolítica da antipolítica ser muito tênue, ou seja, no dado de que a divisão entre a atuação crítica dos cidadãos na arena pública e uma postura de recusa total à política é algo muito frágil. $\mathrm{O}$ problema surge, quando a retórica desses novos coletivos de cidadãos ao invés de proporcionar um círculo virtuoso do accountability, termina por outro lado apreendida por algum oportunista (URBINATI, 2014, p. 110). Neste contexto - que será melhor explorado no próximo ponto - uma vez que a tese ventilada de traição do povo pela classe governante ganhe corpo, existe sempre a possibilidade de que aquele que a defende, se apresente perante a sociedade como o único e efetivo realizador de seus pleitos esquecidos pela odiosa corrupção política ${ }^{32}$ (GHERGHINA \& SOARE, 2013, pp.07-08; URBINATI, 2013, pp. 142-143). ${ }^{33}$ E no caso disso ser aceito, promova no lugar da desilusão um retorno à lógica delegativa.

\section{O PERIGO POPULISTA: OBSTÁCULO, PERSONIFICAÇÃO E ACCOUNTABILITY}

Embora o termo populismo siga sem uma definição precisa de seu conteúdo, ou ainda tenha tantas e tão

\footnotetext{
${ }^{29}$ Na mesma direção, Enrique Peruzzotti e Catalina Smulovitz (2006, p. 10) afirmam que embora a eleição seja o único meio para autorizar a representação política, não representa, porém, a única ferramenta vertical de accountability dos representantes eleitos.

${ }^{30}$ Ver nota de rodapé $n^{\circ} 02$.

${ }^{31}$ Como aponta mais especificamente Enrique Peruzzotti e Catalina Smulovitz (2006, p. 16) o accountability social se por um lado impõe custos de reputação, que são importantes para a sobrevivência dos políticos. Por outro lado, é também condição necessária para a ativação dos mecanismos que possuem dentes. Isto é, em muitos casos, a menos que os mecanismos sociais girem o alarme, os mecanismos vertical eleitoral e horizontais de accountabilitynão começam a funcionar.

32 “[...] no fundamental, envolve o abuso do poder público para qualquer tipo de benefício privado [...]” (MOISÉS, 2013, p. 202).

33 Segundo Cuevas Valenzuela (2006), o populismo se constrói através dos seguintes passos: 1) Um momento inicial onde domina a heterogeneidade do social, expressa na diversidade de grupos, indivíduos e interesses; 2) uma segunda fase em que se produz uma série de demandas ao poder representativo, cada uma delas proveniente de interesses particulares; 3) quando estas demandas iniciais não são satisfeitas e se acumulam, emerge uma certa equivalência entre elas como opostas ao poder; 4) chega então uma quarta fase onde se recorre a algum elemento que condensa as demandas ou as representa simbolicamente; 5) esse elemento é investido com uma significação afetiva que transborda as possibilidades conceituais e lógicas de representar a totalidade e a plenitude social.
} 
diversas até o ponto de ser considerado uma caótica Babel. É quase consenso entre distintos autores, que o mesmo encerra uma convocação direta do povo ${ }^{34}$ como fonte da soberania, em contraposição à representação oficial (ZANATTA, 2014, pp. 17, 23). Quer dizer, o populismo trata-se essencialmente de um fenômeno composto tanto por uma dimensão discursiva, que separa a sociedade em dois polos para uma luta de cariz maniqueísta entre eles. Quanto também é formado por uma dimensão mobilizadora, que no mínimo almeja substituir as elites dirigentes já estabelecidas, por outra (s) mais identificada (s) com a cidadania. E no máximo, busca a refundação de toda a ordem institucional tal como posta (ROBERTS, 2015, pp. 141-142).

$\mathrm{Na}$ base disso, encontra-se sempre a reação a uma percepção de crise. Não uma crise qualquer, mas sim aquela, fruto de um momento em que parte significativa da população de um país conclui que o desacordo entre a "democracia imaginada" e a "democracia real" se acha em proporções intolerantes. ${ }^{35}$ Isso porque, frente ao surgimento de elementos de desagregação social, como uma guerra, a intensificação de fluxos migratórios indesejáveis, ou ainda a ineficiência dos serviços públicos. Caso a representação política se apresente inapta para oferecer respostas a esses problemas, termina a mesma por parecer para a sociedade, mais um obstáculo inútil que separa o povo da satisfação de sua vontade, do que um contributo favorável para lidar com as referidas demandas (ZANATTA, 2014, pp. 45, 47, 64). ${ }^{36}$

Em tal cenário, considerando que é quando surge e ganha protagonismo a figura do líder. No caso, alguém que se intitula e assim por muitos é aceito, como a única alternativa viável - pois afastada da classe política - para satisfazer os pleitos ignorados da sociedade (SORJ \& MARTUCCELLI, 2008, pp. 205-206). Se por um lado, é bem verdade que o mesmo pode ser tomado, à princípio, enquanto um saldo positivo do populismo, pois possui o condão de reaproximar diretamente representantes e representados. Por outro também, não é incorreto afirmar, analisando mais a detidamente a questão, que o populismo esconde uma característica negativa na sua realização: o empoderamento personalista (PERUZZOTTI, 2008, p. 110 ; ZANATTA, 2014, pp. 63, 65).

E no Brasil pós-2013, ao emergir um novo ciclo de protestos, marcado, como já visto, pelo fato da indignação social com os serviços públicos, transbordar-se ao ponto de constituir uma mobilização difusa de monitoramento da representação (BRINGEL \& PLEYERS, 2015, p. 08). Trata-se de um temor que não pode ser descartado. Sobretudo, quando se observa que ao lado de tal atitude, os dados da última eleição demonstram

\footnotetext{
${ }^{34}$ Como explica de forma didática a cientista política Paulina Espejo (2015) “[...] o povo no discurso populista é mais uma construção simbólica ou normativa, do que uma referência a uma coletividade concreta de indivíduos [...]”.

35 Talvez o termo que melhor expresse a situação nem seja "crise", aqui usado apenas como um facilitador para o desenvolvimento do texto. Neste sentido vale a menção de que a expressão "apodrecimento constitucional”, cunhada por Jack Balkin (2018), esteja mais apropriada.

${ }^{36}$ Questionando quem suporta o populismo e o que atrai as pessoas a ele, Spruyt, Keppens e Droogenbroeck (2016, pp. 337, 344), em recente trabalho empírico, chegaram à conclusão, vale destacar, de que a tese segundo a qual pessoas que se sentem vulneráveis econômica, culturalmente, e etc., os chamados, perdedores da globalização, possuem uma tendência maior de suportar o populismo do que aquelas que não se encontram em igual situação.
} 
claramente um desencanto dos cidadãos com a política. O que se materializa no alto número de votos em branco, votos nulos e de abstenções, nas mais distintas localidades geográficas do país. ${ }^{37}$ Bem como, no indicativo de predileção por candidatos que se apresentam como novidade, ou que ostentam um perfil técnico, o que se manifesta na eleição do empresário João Dória para prefeito da cidade de São Paulo, apenas para citar o exemplo mais expressivo e conjugador dos dois tipos. ${ }^{38}$

Nesse profícuo contexto, prejudicado ainda mais pelas notícias cotidianas de utilização indevida dos recursos públicos, divulgadas no âmbito da operação "lava-jato" ${ }^{39} \mathrm{O}$ que vale destacar, também compromete a percepção das pessoas sobre as vantagens da democracia em comparação às suas alternativas. ${ }^{40}$ Já que ao transpor a imagem de que tal conduta é parte da rotina da política, isso desqualifica a primeira como capaz de controlar o abuso do poder (MOISÉS, 2013, p. 202). A ameaça populista de fato reside no caso de um pretenso outsider, advogar que o sistema representativo é o inimigo da sociedade, e ao mesmo tempo se vender como o mais qualificado para encarnando-a, tudo reordenar (ROSANVALLON, 2015, p. 260).

Algo que caso encontre guarida no seio social, como abre a porta para o exercício do poder enquanto posse e não enquanto ocupação (ARDITI, 2007, p. 83). Já que sob a ótica populista, porque a vontade do povo deve se sobrepor às instituições e aos estratos sociais. ${ }^{41}$ Isso faz da eleição um processo de autorização plebiscitária, que exatamente por assim ser e para o sucesso daquela tarefa, exclui toda e qualquer propensão de accountability (URBINATI, 1998, p. 119; TORRE, 2013, p. 18). Logo, é por tal razão que se assume desde o início deste paper, o risco que o populismo traz consigo para a ideia de que a democracia brasileira estaria de mudança.

Afinal, se o que caracteriza a democracia delegativa é o fato do poder executivo ser pouco accountable (KENNEY, 2003, p. 71). E se o que identifica a democracia contínua é a realidade de representantes eleitos mesmo o presidente da república - sofrerem o escrutínio contínuo dos cidadãos - o que devido a um surto social de desconfiança, favorece o serviço realizados pelos órgãos que compõem o accountability horizontal

\footnotetext{
${ }^{37}$ Conforme informações constantes do site do Tribunal Superior Eleitoral, apenas no $1^{\circ}$ turno das eleições de 2016, aproximadamente 30\% dos eleitores aptos a votar no Brasil, ou votaram em branco, ou nulo, ou não compareceram às urnas. Pesquisa disponível em: > http://www.tse.jus.br/imprensa/noticiastse/2016/Novembro/se gundo-turno-das-eleicoesmunicipais-2016-registra-aumento-de-abstencoes<. Acesso em: 10/03/2017.

${ }^{38}$ Como aponta Carlos de la Torre (2010, p. 120) isso se dá pela ideia tais políticos, devido ao sucesso particular em outras áreas que não a política, seriam capazes de resolver os problemas políticos pragmaticamente.

${ }^{39}$ Como salienta José Murilo de Carvalho (2016, p. 235), não que a corrupção seja coisa nova entre nós. Na verdade, o que certamente cresceu - e a operação lava-jato à despeito das inúmeras críticas especializadas que contra ela são feitas, pode sim ser tomada como um exemplo disso - foi a sua visibilidade.

${ }^{40}$ Aqui vale mencionar a pesquisa Ibope sobre o momento político no país, realizada entre os dias 14 e 18 de abril de 2016. Segundo a qual, para 34\% dos entrevistados não faz qualquer diferença se um regime é democrático ou não. Índice que no ano de 2014 era de apenas 18\% Disponível em: > http://www.ibopeinteligencia.com/noticias-e-pesquisas/ap enas-14-dos-brasileiros-sedizem-satisfeitos-com-o-funcionamento-da-democracia/<. Acesso em: 10/03/2017.
} 
(CHERESKY, 2015, pp. 104-105). É óbvio, que na eventualidade dessa desconfiança migrar do papel de alimento da atuação negativa, para a aderência ao discurso fácil de alguém que se apresente como o defensor dos interesses populares, historicamente ignorados por uma elite política refratária. Como em tal percurso é certa a tendência de que quem o lidera, incriminará os elementos de accountability com a alegação retórica de que estes querem reverter os desejos do povo, nele corporificados. ${ }^{42}$ No pior dos mundos, ou o resultado daí em diante é o autoritarismo. Ou, no melhor deles, e uma vez que os ocupantes de cargos representativos não estejam constrangidos a render contas de seus atos, apenas eleitoralmente (MAINWARING, 2003, p. 05; VITTORI, 2015, p. 06), por certo é o (re) instauro da realidade delegativa.

\section{CONCLUSÃO}

O presente trabalho teve por objetivo apresentar algumas considerações a respeito da ameaça que representa o populismo para a tese de que a democracia brasileira se acharia em uma etapa de transição de um tipo para outro. Nesta senda o que se quis inicialmente demonstrar foi que apesar do instituto da representação ser algo inevitável na contemporaneidade. Dada a perda recente da proeminência dos partidos na tarefa de intermediação de interesses, e em razão deste papel ter migrado para um grande número de coletivos de cidadãos, calcados, cada qual, numa atuação contestatória, sob forte inspiração da desconfiança. Sem demora, porque esse processo se entende também estar ocorrendo no Brasil, sobretudo, após os movimentos do ano de 2013, é por tal razão que se sustentou que a democracia delegativa - marcada pela quase inexistência do accountability - poderia estar cedendo espaço para outra chamada de contínua - onde o accountability social é cotidiano e o horizontal por isso mais robusto.

Ocorre, porém, que sem se desconsiderar neste âmbito, situações extremas, mas viáveis de se dar, como a possibilidade de que a desilusão entre os cidadãos possa se degenerar em ódio para com os ocupantes de cargos eletivos, e a de que a insatisfação social possa ser absorvida pela retórica de alguém que se apresente enquanto líder do trabalho de resgate do poder popular, surrupiado por aqueles. Como são o conjunto delas, ao fim, responsáveis pela implementação do populismo - onde as instituições possuem um valor meramente instrumental frente ao will of the people. Não por outra razão é que se pode concluir que nos mais distintos lugares onde isso ocorra, e o Brasil não é exceção. Estabelecida a lógica de que as autoridades públicas possuem pouco dever de render contas

\footnotetext{
${ }^{41}$ Neste sentido, complementa ainda Nádia Urbinati, afirmando que "[...] de acordo com o populismo, as instituições, e acima de tudo o parlamento e as eleições, possuem um valor apenas instrumental. É o povo - a maioria no caso - que diretamente legitima as instituições, sem nenhuma outra medição, senão sua vontade atual [...]”.
} 
de seus atos, consequentemente isso se converte em sustento para a (re) inauguração da democracia delegativa e rompe com qualquer atividade de modificação desta para a de tipo contínua.

\title{
THE POPULIST DANGER IN THE HYPOTHESIS OF TRANSITION FROM THE DELEGATIVE TO THE CONTINUING DEMOCRACY IN BRAZIL
}

\begin{abstract}
Since 2013, the world watches Brazil turns into a big stage of claims. Dissatisfactions of the most varied types, demands of more plural grades, ideologies from the most diverse, seems each one wants to put light on some faulty aspect of national political life. Underlying this reality, however, this article assumes that although there are different readings and responses, what does it assume' to be in play in the center of these movements is the Democracy model that we want to transmit to the next generations. After all, for being the democracy a constantly changing and improving process, the emergence on the political scene of more distrustful citizens to the bodies vested with power, if at first, because it favors accountability, it can have the positive point of referring Brazil to the exit of a delegative experience and to move to a continuous type. On the other hand, it is also possible that the general distrust manipulated by populism may end up favoring continuity.
\end{abstract}

Keywords: Democracy; Distrust; Accountability; Populism.

\section{BIBLIOGRAFIA}

ANDERSON, Perry. El nuevo viejo mundo. Madrid: Akal, 2012.

ARDITI, Benjamin. Politics at the edge of liberalism. Edinburgh: Edinburgh University Press, 2007.

\footnotetext{
${ }^{42}$ No mesmo sentido, mas em outros termos, afirma Carlos de la Torre (2010, p. 172) que "[...] o populismo, nem sempre respeita as normas e as instituições da democracia liberal, porque suas normas e procedimentos são vistos como impedimentos para a expressão da autêntica e homogênea vontade do povo, que não é outra, senão aquela do líder [...]”.
} 
AVRITZER, Leonardo. Impasses da democracia no Brasil. Rio de Janeiro: Civilização Brasileira, 2016.

AZAMBUJA, Darcy. Introdução à ciência política. São Paulo: Globo, 2008.

BALKIN, Jack. Constitutional rot. In: SUNSTEIN, Cass (Org.). Can it happen here? Authoritarianism in America. New York: Dey Street Books, 2018.

BOBBIO, Norberto. Teoria Geral da Política. Rio de Janeiro: Elsevier, 2000.

Estado, Governo e Sociedade. São Paulo: Paz e Terra, 2003.

O futuro da democracia. São Paulo: Paz e Terra, 2004.

BONAVIDES, Paulo. Ciência Política. São Paulo: Malheiros, 2000.

Teoria do Estado. São Paulo: Malheiros, 2003.

BRINGEL, Breno; PLEYERS, Geoffrey. Junho de $2013 \ldots$ dois anos depois. Polarização, impactos e reconfiguração do ativismo no Brasil. In: Nova Sociedade, V. 2015, nº 02, 2015.

BURKE, Sara. O que uma época de protestos globais diz a respeito da eficácia dos direitos humanos como linguagem para alcançar mudanças sociais. In: SUR. Revista Internacional de Direitos Humanos. V. 11. №. 20, 2014

CANOTILHO, José Joaquim Gomes. Direito constitucional e teoria da constituição. Coimbra: Almedina, 2003.

CARNEIRO, Henrique Soares. Apresentação - rebeliões e ocupações de 2011. In: HARVEY, David. Et al. Occupy. Movimentos de protesto que tomaram as ruas. São Paulo: Boitempo e Carta Maior, 2012.

CARVALHO, José Murilo de. Cidadania no Brasil. O longo caminho. Rio de Janeiro Civilização Brasileira, 2016.

CASTELLS, Manuel. Redes de indignação e esperança. Rio de Janeiro: Zahar, 2013.

CAVALCANTI, Themístocles Brandão. Introdução à ciência política. Rio de Janeiro: Fundação Getúlio Vargas, 1969. 
CHERESKY, Isidoro. La politica despues de los partidos. Buenos Aires: Prometeo Libros, 2006 Comentario a propósito del Estado y la democracia. In: MARIANI, Rodolfo. Democracia/Estado/Ciudadanía. Hacia un Estado de y para la democracia en América Latina. Lima: Sede PNUD, 2008.

Ciudadanía y democracia continua. In: Revista Temas y Debates. № 22, 2011.

El nuevo rostro de la democracia. Buenos Aires: Fondo de Cultura Económica, 2015.

COCCO, Giuseppe. Mobilização reflete nova composição técnica do trabalho immaterial das metrópoles. Entrevista especial com Giuseppe Cocco. Disponível em: > http://www.hu.unisino s.br/entrevistas/521331mobilizacao-reflete-nova-composicao-tecnica-do-trabalho-imaterial-das-metropoles-entrevista-especial-comgiuseppe-cocco<. Acesso em: 27/05/2015

CROUCH, Colin. Posdemocracia. Madrid: Taurus, 2004.

DALLARI, Dalmo de Abreu. Elementos de teoria geral do Estado. São Paulo: Saraiva, 2003.

DELLA PORTA, Donatella. Critical trust: social movements and democracy in times of crisis. In: Cambio. № 04, 2012.

ESPEJO, Paulina Ochoa. The people between procedure and populism. In: TORRE, Carlos de la (Org.). The promise and perils of populism: global perspectives. Lexington: University press of Kentucky, 2015.

GARGARELLA, Roberto. Crisis de representación y constituciones contramayoritarias. In: Isonomia, no 02, 1995.

GHERGHINA, Sergiu; SOARE, Sorina. Introduction: populism. A sophisticated concept and diverse political realities. In: GHERGHINA, Sergiu; MISCOIU, Sergio; SOARE, Sorina (Orgs.). Contemporary populism: a controversial concept and its diverse forms. Cambridge: Cambridge Scholars Publishing, 2014.

GOHN, Maria da Glória. A sociedade brasileira em movimento: vozes das ruas e seus ecos politicos e sociais. In: Caderno CRH. V. 27, nº 71, 2014. 
HAMILTON, Alexander; MADISON, James; \& JAY, John. O Federalista. Belo Horizonte: Líder, 2003.

LIMONGI, Fernando. Vontade popular pronta e acabada é presunção. Disponível em: >http:// www.fflch.usp.br/centrodametropole/upload/aaa/264-artigo_valor_limongi_1\%207\%202013. pdf<. Acesso em: 27/05/2015.

KEANE, John. The life and death of democracy. New York: W. W. Norton \& Company, 2009.

KENNEY, Charles. Horizontal accountability: concepts and conflicts. In: MAINWARING, Scott; WELNA, Christopher (Orgs.). Democratic accountability in Latin America. New York: Oxford University Press, 2003.

KLINGEMANN, Hans-Dieter; FUCHS, Dieter. Citizens and the State. Gloucestershire: Clarendon Press, 1998.

MAINWARING, Scott. Introduction: democratic accountability in Latin America. In: MAINWARING, Scott; WELNA, Christopher (Orgs.). Democratic accountability in Latin America. New York: Oxford University Press, 2003.

MALINI, Fábio. et al. \#VemPraRua: narrativas da revolta brasileira. 2014. In: XII Congresso da Associação Latinoamericana de Investigadores da Comunicação (ALAIC), 2014. Disponível em: > http://labic.net/wpcontent/uploads/VemPraRua-Narrativas-da-Revolta-brasileira.pdf<. Acesso em: 16/01/2017.

MALINI, Fábio; ANTOUN, Henrique. @ internet e \# rua. Ciberativismo e mobilização nas redes sociais. Porto Alegre: Sulina, 2013.

MANIN, Bernard. Los principios del gobierno representativo. Madrid: Alianza editorial, 1997. A democracia do público reconsiderada. In: Novos Estudos. No 97, 2013.

MILL, John Stuart. El gobierno representativo. Madrid: Victoriano Suarez, 1878.

MOISÉS, José Álvaro. Democracia e desconfiança das instituições democráticas. In: MOISÉS, José Álvaro (Org.). Democracia e Confiança. Por que os cidadãos desconfiam das instituições públicas? São Paulo; Editora da Universidade de São Paulo, 2010.

Corrupção política e democracia no Brasil contemporâneo. In: MOISÉS, José Álvaro; MENEGUELLO, 
Rachel (Orgs.). A desconfiança política e os seus impactos na qualidade da democracia. São Paulo: Editora da Universidade de São Paulo, 2013.

MONTESQUIEU, Charles de Secondat, Baron de. O espírito das leis. São Paulo: Martins Fontes, 1996.

NOBRE, Marcos. Imobilismo em movimento. Da abertura democrática ao governo dilma. São Paulo: Companhia das Letras, 2013.

NORRIS, Pippa. Democratic phoenix: reinventing political activism. New York: Cambridge University Press, 2002.

O’DONNELL, Guillermo. Democracia delegativa? In: Novos Estudos. № 31, outubro, 1991.

Horizontal Accountability: The Legal Institutionalization of Mistrust. In: MAINWARING, Scott; WELNA, Christopher (Orgs.). Democratic accountability in Latin America. New York: Oxford University Press, 2003.

PERUZZOTTI, Enrique. Populismo y representacion democratica. In: TORRE, Carlos de la; PERUZZOTTI, Enrique (Orgs.). El retorno del pueblo. El populismo y nuevas democracias en América Latina. Quito: FLACSO, 2008.

Accountability deficits on delegative democracy. In: BRINKS, Daniel; LEIRAS, Marcelo; \& MAINWARING, Scott. Reflections on uneven democracies. The legacy of Guillermo O'Donnell. Baltimore: Johns Hopkins University Press, 2014.

PERUZZOTTI, Enrique; SMULOVITZ, Catalina. Social accountability: an introduction. In: PERUZZOTTI, Enrique; SMULOVITZ, Catalina (Orgs.). Enforcing the rule of law: social accountability in the new Latin American democracies. Pittsburgh: University of Pittsburgh Press, 2006.

PITKIN, Hanna Fenichel. The concept of representation. Berkeley: University of California Press, 1967.

PUJOL, Antoni Francesc Tulla i; ROCHA, Fernando Goulart; SAMPAIO, Fernando dos Santos. Manifestações populares no Brasil atual: sociedade civil em rede e reinvindicações sobre o poder politico. In: XII Colóquio Internacional de Geocrítica. El control del espacio y los espacios del control. 2014. Disponível em: 
>http://www.ub.edu/geocrit/coloquio2014/Anto ni\%20Francesc\%20Tulla\%20i\%20Pujol.pdf<. Acesso em: $16 / 01 / 2017$.

QUIROGA, Hugo. Esfera pública, política y ciudadanía. Dilemas de la política democrática argentina. In: Revista Internacional de Filosofia Política, nº 07, maio, 1996.

Después de 30 años. Que democracia estamos construyendo. In: PolHis, Año 06, Número 12, Segundo semester de 2013.

ROBERTS, Kenneth. Populism, political mobilizations, and crises of political representation. In: TORRE, Carlos de la (Org.). The promise and perils of populism: global perspectives. Lexington: University press of Kentucky, 2015.

ROSANVALLON, Pierre. La contrademocracia. La politica en la era de la desconfianza. Buenos Aires: Manantial, 2007.

La contrademocracia. La politica en la era de la desconfianza. Buenos Aires: Manantial, 2015.

ROUSSEAU, Dominique. Radicaliser la démocratie. Propositions pour une refondation. Paris: Seuil, 2015.

SADER, Eder. Quando novos personagens entram em cena: experiências, falas e lutas dos trabalhadores da grande São Paulo (1970-1980). Rio de Janeiro: Paz e Terra, 2001.

SAGNIÈRES, Louis. The internet and the rise of a transnational counter-democracy. In: Ritsumeikan Studies in Language and Culture. V.23, nº 04, 2012.

SIEYÈS, Emmanuel Joseph. A constituinte burguesa. Rio de Janeiro: Lumen Juris, 2001.

SORJ, Bernardo; MARTUCCELLI, Danilo. El desafio latino-americano. Cohesion social y democracia. Rio de Janeiro: Centro Edelstein de Pesquisas Sociais, 2008.

SPRUYT, Bram; KEPPENS, Gil; DROOGENBROECK, Filip van. Who supports populism and what attracts people to it? In: Political research quarterly, V. 69, nº 02, 2016. 
TORRE, Carlos de la. Populist seduction in Latin America. Athens: Ohio University Press, 2010.

The people, populism, and the leader's semi-embodied power. In: Rubrica Contemporanea, V. 02, nº 03, 2013.

URBINATI, Nadia. Democracy and populism. In: Constellations, V. 05, nº 01, 1998.

The populist phenomenon. In: Raisons Politiques. No 51, 2013.

A revolt against intermediary bodies. In: Constellations. V.22, №. 04, 2015.

VALENZUELA, Hermán Cuevas. Recensiones: Laclau, Ernesto. La razón populista. In: Revista de ciencia política. V.26, nº 01, 2006.

VERGOTTINI, Giuseppe de. Derecho constitucional comparado. México: Universidad Nacional Autonoma de Mexico, 2004.

VITTORI, Davide. Is populism changing the political representation of western democracies? In: Journal of Political Sciences \& Public Affairs, V. 03, nº 01, 2015.

ZANATTA, Loris. El populismo. Buenos Aires: Katz, 2014.

ZIPPELIUS, Reinhold. Teoria general del Estado. Mexico: Universidad Nacional Autonoma de Mexico, 1985.

Trabalho enviado em 29 de junho de 2018

Aceito em 04 de setembro de 2018 